\title{
Quantifying the effectiveness of ecological restoration projects on long-term vegetation dynamics in the karst regions of Southwest China
}

Tong, Xiaowei; Wang, Kelin; Yue, Yuemin; Brandt, Martin Stefan; Liu, Bo; Zhang, Chunhua; Liao, Chujie; Fensholt, Rasmus

\section{Published in:}

International Journal of Applied Earth Observation and Geoinformation

DOI:

10.1016/j.jag.2016.09.013

Publication date:

2017

Document version

Peer reviewed version

Document license:

CC BY-NC-ND

Citation for published version (APA):

Tong, X., Wang, K., Yue, Y., Brandt, M. S., Liu, B., Zhang, C., Liao, C., \& Fensholt, R. (2017). Quantifying the effectiveness of ecological restoration projects on long-term vegetation dynamics in the karst regions of Southwest China. International Journal of Applied Earth Observation and Geoinformation, 54, 105-113. https://doi.org/10.1016/j.jag.2016.09.013 

dynamics in the karst regions of Southwest China

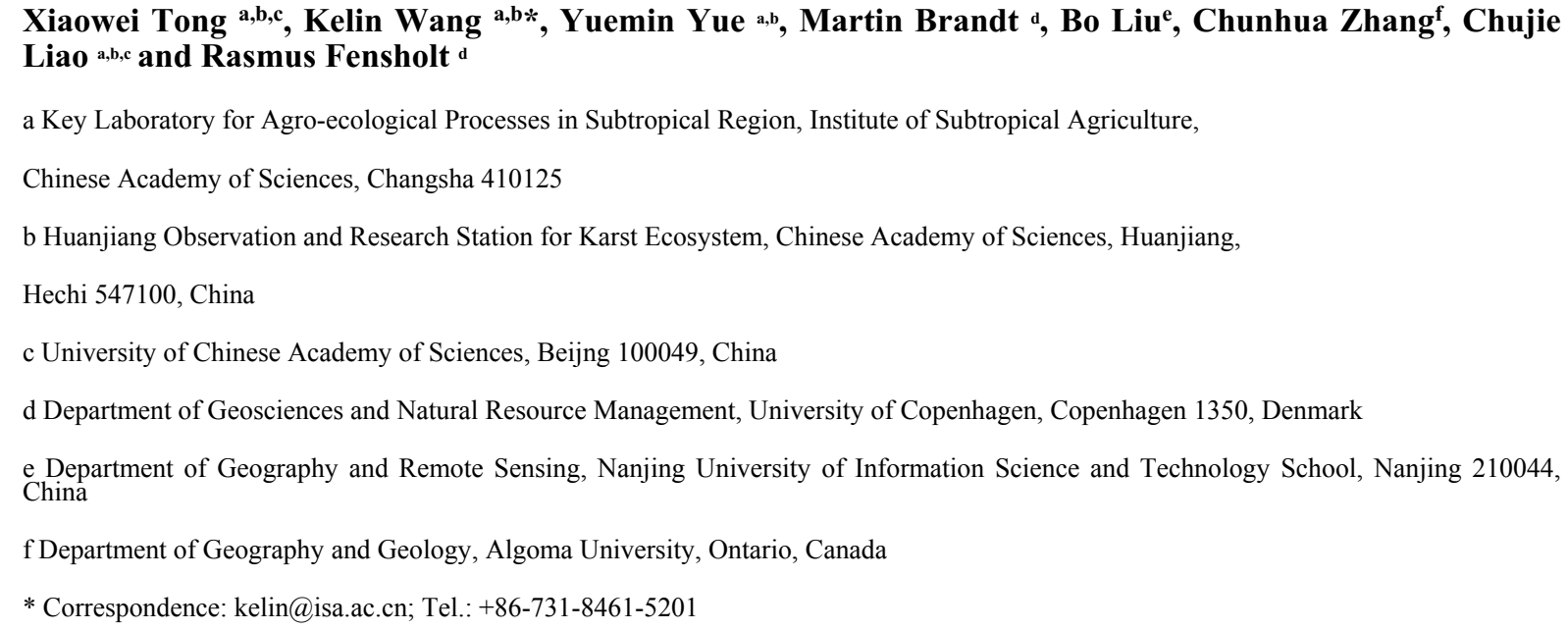

ABSTRACT

To alleviate the severe rocky desertification and improve the ecological degradation conditions in Southwest China, the national and local Chinese governments have implemented a series of Ecological Restoration Projects (ERPs) since the late 1990s. This study proposes a remote sensing based approach to evaluate the long term efforts of the ERPs started in 2000. The method applies a time series trend analysis of satellite based vegetation data corrected for climatic influences to reveal human induced vegetation changes. The improved residual method is combined with statistics on the invested project funds to derive an index, Project Effectiveness Index (PEI), measuring the project effectiveness at county scale. High effectiveness is detected in the Guangxi Province, moderate effectiveness in the Guizhou Province, and low and no effectiveness in the Yunnan Province. Successful implementations are closely related to the combined influences from climatic conditions and human management. The landforms of Peak Forest Plain and Peak Cluster Depression regions in the Guangxi Province are characterized by temperate climate with sufficient rainfall generally leading to a high effectiveness. For the karst regions of the Yunnan and Guizhou Provinces with rough terrain and lower rainfall combined with poor management practices (unsuitable species selection, low compensation rate for peasants) only low or even no effect of project implementations can be observed. The distribution is however not homogeneous and counties with a high project effectiveness in spite of complex natural conditions were identified, but also counties with negative vegetation trends despite favorable conditions and high investments. The proposed framework is expected to be of high relevance in general monitoring of the successfulness of ecological conservation projects in relation to invested funds. 
Keywords: RESTREND, Grain to Green Program, rocky desertification, growing season NDVI, Yunnan, Guizhou, Guangxi

\section{Introduction}

Rocky desertification is a typical type of land degradation by which a karst area covered by vegetation and soil is transformed into a rocky landscape with limited soil and vegetation resources (Wang et al., 2004; Yuan, 1997). Rocky desertification is influenced by the combined circumstances of geology, geomorphology, soil, warm and wet climate, vegetation, as well as human overexploitation of natural resources (Liu et al., 2008; Wang et al., 2004; Xu and Zhang, 2014). The rocky desertification in the karst regions of Southwest China has been identified as the most severe ecological problem threatening the area (Wang et al., 2004; Yuan, 1997; Yue et al., 2010). Up to 82\% of the rocky desertification areas are concentrated in the Yunan, Guizhou, and Guangxi Provinces (Jiang et al., 2014). To protect and improve the ecological environment, the state and local Chinese governments have launched a series of ecological restoration projects (ERPs), such as the Natural Forest Protection Project, the Grain to Green Program, and the Karst Rocky Desertification Comprehensive Control and Restoration Project. However, evaluation of the effectiveness of these projects focuses on the north of China (Huang et al., 2013; Li et al., 2016; Wu et al., 2014, 2013; Zhang et al., 2012, 2016) and the success of the ERPs in Southwest China is uncertain (Trac et al., 2007; Xu et al., 2006).

The primary objectives of ERPs are to protect the existing forests and to increase vegetation coverage by means of afforestation (i.e., planting on previously barren wastelands), reforestation, and cropland to forest/grassland conversion. An increase/decrease in vegetation can thus be interpreted as progress/regression of the effectiveness of ERPs. However, apart from ERPs, also climatic changes influence vegetation dynamics (Choi, 2004; Seabrook et al., 2011), and therefore, to evaluate the performance of large-scale ERPs, a prerequisite is to distinguish between human and climate-induced vegetation changes.

Field surveys can generate accurate information related to vegetation dynamics and their drivers, but in situ observations are costly, time-consuming and spatially limited (Li et al., 2006; Xiao et al., 1995). Due to the large area coverage and long time span, satellite based imagery has become a widely used tool in ecological conservation and one of the most important data sources for monitoring vegetation dynamics at large scales (Nemani et al., 2003; Pettorelli et al., 2005; Tucker et al., 2001). The normalized difference vegetation index (NDVI), based on the red and near-infrared spectrum, has shown to be efficient for sensing the green vegetation and monitoring global and regional trends as 
well as the variability of vegetation (Huete et al., 2002; Pinzon and Tucker, 2014; Running and Nemani, 1988). For areas of pronounced seasonality (as in this study), the growing season NDVI (GSN) has proven to be a robust approximation of the biomass production of a given year (Mbow et al., 2013; Tong et al., 2016).

Numerous studies have applied NDVI time series in China showing a recent increase in vegetation productivity in the karst regions (Cai et al., 2014; Tong et al, 2014; Xu and Zhang, 2014; Wang et al., 2007). Yet, it remains to be determined if these positive vegetation trends are driven by climatic or human factors and if any relationships with ERPs exist. Moreover, time series based on a short period (less than 30 years), do often not meet the requirements of covering both pre and post conditions of the temporal dynamics of vegetation changes in relation to implementation of ERPs, and trends are usually not linear over a longer period.

Applying a long term Earth Observation (EO) data set allows to separate human activities from climatic influences on vegetation dynamics by developing a NDVI-climate model, and monitor the residuals between observed and predicted (using climate variables) vegetation trends (Archer, 2004; Evans and Geerken, 2004; Herrmann et al., 2005; Wessels et al., 2007). A number of researchers have realized that it was unreasonable to develop NDVI-climate models by using data over the full time series without considering the existing human impacts, especially the large scale implementation of ERPs in later years (Cao et al., 2006; Horion et al., 2016; Wang et al., 2009). This has been done by introducing a turning point and establishing the model on a reference period of little human interference to predict the vegetation for a period which is supposed to be heavily influenced by humans (Cao et al., 2006; Wang et al., 2009; Li et al., 2011). However, this turning point is usually defined a priori to EO time series analysis. Here we expand on this approach by identifying the turning point from the vegetation time series itself to define a reference period where ERPs impact was not detectable. Without additional information (e.g. statistical or field data), interpretations of residual trends are speculative and the assessment of the efficiency of ERPs remains vague. By using a 30 year time series of NDVI (GIMMS-3g) and climate data (temperature and rainfall) we combine the results of the human induced vegetation trend analysis with statistical data of ERPs, more specifically the Grain to Green Program, which aims at convert farmland into forests and grasslands (Jia et al., 2014; Liu et al., 2014).

The overall objective of this study is thus to assess the effectiveness of ERPs (implemented by the state and local Chinese governments) on long-term vegetation dynamics across Southwest China in recent decades. This is achieved by (1) removing the effects of climate (rainfall and temperature) thereby highlighting human induced vegetation changes and, (2) relating the human induced vegetation trends to the project funds invested at county scale. 
The study area includes the Yunnan, Guizhou and Guangxi Provinces, Southwest China (Fig. 1a).

114 Dominated by monsoon climate, the study area has a mean annual temperature of $17.6^{\circ} \mathrm{C}$ and a mean annual precipitation of $1021 \mathrm{~mm}$. The region has high landscape heterogeneity with a large altitudinal difference from Northwest of Yunnan Plateau (about 4000 m.a.s.1.) to lowland area such as the Xunjiang Plain (about 30 m.a.s.l.) (Fig.1b). The major land cover types are evergreen and deciduous shrubs (42\%), evergreen needle leaf forests (17\%), evergreen and deciduous broad leaf forests $(15 \%)$, evergreen broad leaf forests (12\%) and farmland (10\%) (Wang et al., 2007). The bedrock of the karst regions are dominated by pure carbonate $(25 \%)$ and impure carbonate $(23 \%)$ whereas the bedrock for the rest of the region consists of clastic rocks (non-karst region) (Tong, 2009). The study area can be divided into eight (project-) regions based on topography, lithology and geological structural conditions (Yuan, 2014) (Fig. 1c). In this study, the Grain to Green Program serves as a representative ERP which started in 2000 and was implemented within administrative units. The program compensates participating farmers for converting their cropland back to forests or grasslands with a cash subsidy, grain subsidy, and free saplings at the start of reforesting (SFAB, 2000; Trac et al., 2007).
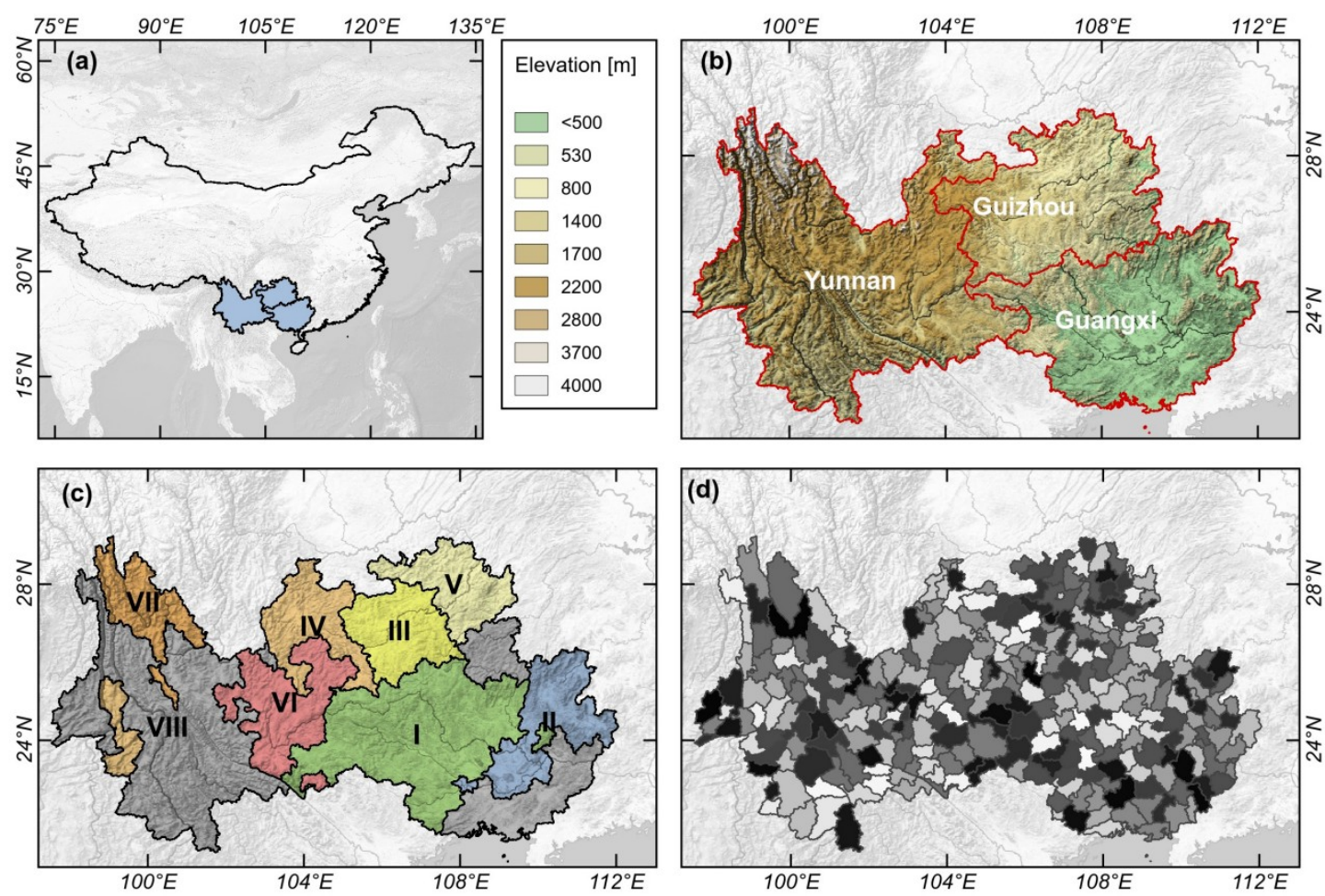

Figure 1 (a) Location of the study area in China, (b) Elevation of the three provinces of the study area, (c) location and extent of the different project regions: (I) Peak Cluster Depression, (II) Peak Forest Plain, (III) Karst Plateau, (IV) Karst Gorge, (V) Karst Trough Valley, (VI) Karst Basin, (VII) Middle-high Hill and (VIII) non- karst region respectively, (d) The administrative counties of the study area. 
Data and processing

This study uses the GIMMS-3g NDVI, available in a bimonthly temporal resolution of $8 \mathrm{~km}$ spatial resolution from 1982 to 2011 (Pinzon and Tucker, 2014). To reduce contamination caused primarily by cloud and atmospheric variability, we calculated a monthly NDVI by choosing the maximum value of the fortnightly data set. Then the values from April to November were averaged to obtain the growing season NDVI for each year from 1982 to 2011 (Tong et al., 2016).

Monthly temperature and rainfall data for 71 weather stations within Southwest China from 1982 to 2011 were obtained from the China Meteorological Data Sharing Service System (http: //cdc.cma.gov.cn). We applied ordinary Kriging to generate gridded fields of temperature and rainfall with the same resolution and geographic coordinate system as those of the NDVI data set. County level statistical data of the Grain to Green Program including project areas (e.g. areas for mountain closure, afforestation, and cropland conversion) and funding (e.g. money allocated for grain and seeding, and cash) from 2001 to 2011 were provided by the Forestry Bureau of the Yunnan, Guizhou and Guangxi Provinces.

\section{Methods}

A linear regression was applied to detect and analyze trends in annual GSN. The slope of the regression was derived as an indication of the direction and magnitude of trends (Fensholt and Proud, 2012; Tong et al., 2016). The GSN trends were categorized into three types: increase (positive slope), decrease (negative slope) and stable (no significant slope at the 95\% level).

In the present study, we utilized the Sequential version of Mann-Kendall test statistic (Mohsin and Gough, 2009) to detect a potential turning point in the annual GSN trend. This technique calculates two statistical measures, which are the sequential values of a reduced or standardized variable (Chatterjee et al., 2014). A forward sequential statistic is estimated using the original time series, and a backward sequential statistic is estimated in the same way but starting from the end of the series. The year of the intersection between the curves of the two statistics indicates a potential turning point, which is tested for its significance at the $95 \%$ level $(p<0.05)$. For details on the method we refer to Chatterjee et al. (2014).

Assuming that this turning point was caused by the efforts of ERPs, we used this year to separate the time series into two periods. The first period (named reference period hereafter) was characterized as a baseline (reference) where vegetation was not strongly affected by ERPs. The second period (named conservation period hereafter) was characterized by the implementation and efforts of ERPs. In order to separate climate from human induced vegetation trends, we applied the widely used residual method (Evans and Geerken, 2004; He et al., 2015; Huber et al., 2011; Li et al., 2012; 
Wessels et al., 2007). To better reflect the impacts of ERPs on vegetation changes, we used the first (reference) period (rather than the entire period) to develop the multiple regression model between NDVI (response variable) and climate factors (temperature and rainfall as predictors) based on monthly observations. Local conditions (such as geomorphology, hydrology and soil) may influence the relationship between NDVI and climatic variables, and this is especially important in the highly fragmentized terrain of Southwest China. To take this into account, we applied a pixel-based regression, i.e. the NDVI-climate model was calculated for each pixel (Evans and Geerken, 2004). Thus, the NDVI-climate regression model using the monthly data from the first period is given in Eq. (1).

$$
\operatorname{NDVI}(i, m)=\mathrm{a} * \operatorname{Temp}(i, m)+\mathrm{b} * \operatorname{Prec}(i, m)+\mathrm{c}
$$

Where, $i$ is the location of a pixel; $m$ identifies the month; $a$ is the regression coefficient of NDVI and temperature (Temp) of $m$ month; $b$ is the regression coefficient of NDVI and precipitation (Prec) of $m$ month; ${ }^{c}$ is a constant. Only those regions with a significant correlation between NDVI and climate (95\% level) were kept and the regression coefficients were used to predict the monthly NDVI for the conservation period and generate the predicted GSN for these years (which is assumed to be climate driven only). We then calculated the residuals between the observed GSN and the predicted GSN for the conservation period. These residuals are expected to reflect the human signal, i.e. the vegetation trends which cannot be explained by climate. The temporal trend of the GSN residuals was used to monitor human-induced vegetation trends and termed alike in the following. No trend over time means an insignificant impact of human activities on vegetation trends (no significant impact); a decreasing trend indicates vegetation degradation presumably induced by human activities (negative impact); and an increasing trend suggests improved vegetation conditions which cannot be explained by climate and may be attributed to conservation and restoration efforts (positive impact).

To validate these assumptions, we related statistical data on project areas (in $\mathrm{km}^{2}$ ) of the Grain to Green Program at county level with human induced vegetation trends detected by remote sensing within the same county. Project areas were grouped into 4 classes: 0-50 km² (class 1), 50-100 km² (class 2), 100-200 km² (class 3), >200 km² (class 4). As a linear comparison between pixels and project areas is not feasible due to the effectiveness variability between counties, we applied a t-test and box plots to test the difference in the mean value of classes.

In order to assess the project effectiveness, we developed a Project Effectiveness Index (PEI). The PEI is calculated as follows:

$$
P E I=\frac{S_{i}}{R_{i}}
$$

where $S_{i}$ refers to the project intensity, which is the ratio of the sum of the invested funding to the project areas for the conservation period in county i after normalization (ranging from 0 to 1 ). $R_{i}$ is the ratio of pixels with significant increasing residual trends (human induced trends) in the county $i$ (ranging from 0 to 1). Counties without any pixels of significant increasing residual trends were omitted from further analysis. When $S_{i}$ equals 0 , the $P E I$ reaches a minimum; when $\mathrm{S}_{\mathrm{i}}$ equals 1 and $\mathrm{R}_{\mathrm{i}}$ 
is the lowest of all counties, then the PEI reaches the maximum. Consequently, the PEI ranges from 0 to $\frac{1}{\mathrm{R}_{\mathrm{i}}(\min )}$ and a small/high PEI indicate high/low project effectiveness. We classified the counties into three types based on their PEI values to assess the level of project effectiveness. A PEI value less than 1 is deemed as high project effectiveness. Values between 1 and 10 are classified as moderate project effectiveness and values greater than 10 are assigned low project effectiveness.

\section{Results}

\section{Vegetation trends and the turning point}

At regional scale, the GSN has increased significantly at the rate of 0.002 GSN year ${ }^{-1}$ during 1982-2011 ( $p=0.002)$. However, the GSN trends are not monotonically increasing over the entire period. Mann-Kendall test statistics showed that the backward trend of annual GSN of the entire study area intersects the forward trend in the year 2001, which was identified as a turning point (Fig. 2a). The GSN trend was unstable prior to 2001 but steadily positive after this year (Fig. 2b). Based on this turning point, we found an overall insignificant $(p=0.98)$ decreasing trend for the reference period (1982-2000) and a moderate significant increasing trend $(90 \%$ level; $p=0.07)$ for the conservation period (2001-2011) (Fig. 2b).
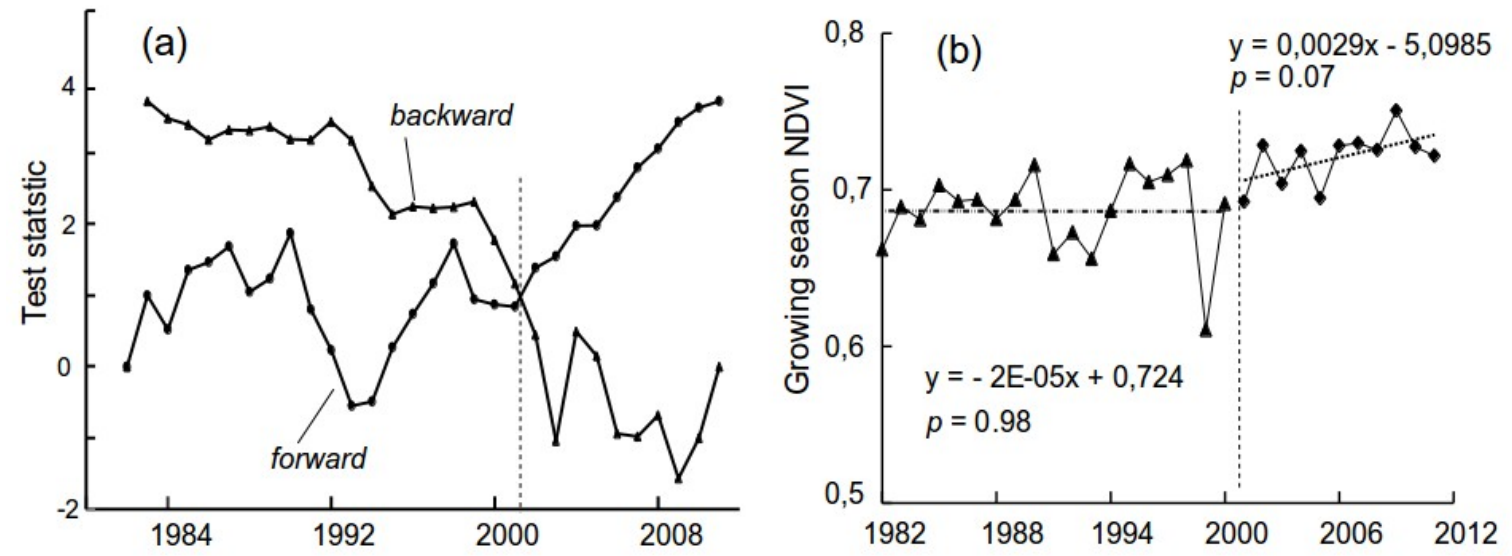

Figure 2 (a) Abrupt changes in annual GSN as derived from Mann-Kendall test statistics, using a forward and backward sequential statistics calculation approach. The year of the intersection is the potential turning point. (b) GSN inter-annual variations and linear trends for the two periods (1982-2000 and 2001-2011).

At pixel scale $(8 \mathrm{~km})$, the trends in annual GSN over the last 30 years showed distinct spatial differences (Fig. 3a). Whereas $45 \%$ of the study area had no significant trend (stable), a significant uptrend (increase) was found for $54 \%$ of all pixels, mostly concentrated in the Guangxi and Guizhou Provinces. In contrast, only $1 \%$ of the study area showed a significant downtrend (decrease) mostly located in the Yunnan Province. Vegetation trends vary greatly between the reference and conservation period (Fig. 3b, c). In the reference period, 94\% of the study area showed no significant 
trend and only $4 \%$ and $2 \%$ were characterized by significant increasing and decreasing (concentrated in the Guizhou Province) trends respectively. However, during the conservation period, vegetation significantly increased in $19 \%$ of the area (primarily in the Guangxi Province). During the conservation period, downtrends were found in the Yunnan Province accounting for $2 \%$ of the study area. The slope difference between these two periods also showed distinct spatial differences (Fig. 3d). Regions where the GSN slope during the conservation period was greater than the reference period (a sign of vegetation growth acceleration) covered $72 \%$ of the study area. The largest slope difference (greater than $0.04 \mathrm{GSN}_{\text {year }}{ }^{-1}$ ) was mainly observed in the Guangxi Province. Areas where the GSN slopes during 2001-2011 were lower than that prior to 2001 (a sign of vegetation growth deceleration) were located especially in the Yunnan Province.

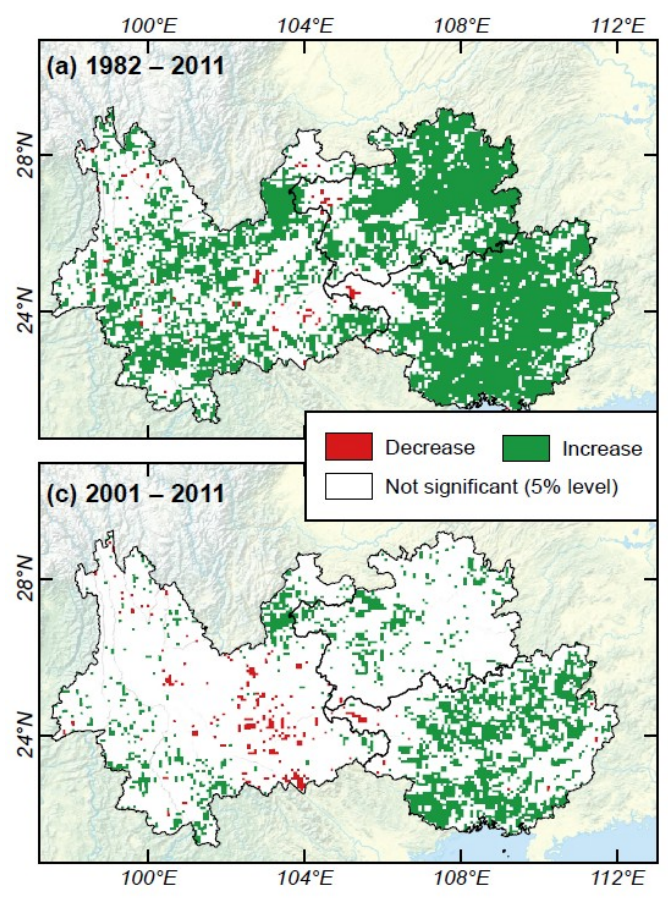

Figure 3 (a-c) Vegetation trends for different periods (a: 1982-2011, b: 1982-2000 and c: 2001-2011) based on the GSN. (d) Vegetation trend slope difference of the reference (1982-2000) and conservation (2001- 2011) periods.

\section{Human induced vegetation trends}

The majority $(96 \%)$ of the pixels had a significant $(p<0.05)$ correlation between NDVI and climate variables (rainfall and temperature) and the analysis was subsequently focused on these regions. Here, $16 \%$ showed a significant impact from human activities, with about $1 \%$ of the pixels having a significant negative human induced trend and $15 \%$ a significant positive trend (Fig. 4a). Human activities showed no significant impact on vegetation dynamics in other regions (84\%). 
Negative trends were found in the middle and east of the Yunnan Province. Here, vegetation growth was lower than it was expected from the climate dynamics, indicating human activities presumably induced the vegetation degradation (negative impact). Positive trends were mostly located in the Guangxi Province, the west portion of the Guizhou Province and the southwestern part of the Yunnan Province. Vegetation in these regions has been greening up to a larger extent than explained by climate alone, suggesting the improved vegetation conditions may be attributed to conservation and restoration efforts (positive impact).

The averaged GSN residuals of each province all showed an increasing trend, but only in the Guangxi Province the trend is moderately significant ( $90 \%$ level; $p=0.064)$. We calculated the mean slope of pixels where the human induced trend was significantly positive for each province, and found the strongest trends located in the Guangxi Province ( 0.0104 GSN year $\left.{ }^{-1}\right)$, followed by Guizhou (0.0088 GSN year-1), and the Yunnan Province (0.0080 GSN year-1). This indicates that the ERPs implemented in the Guangxi Province had a larger positive effect on vegetation than in other provinces. The Yunnan Province had the most negative human induced trends (-0.0075 GSN year $\left.{ }^{-1}\right)$, followed by the Guangxi Province ( $\left.-0.0067 \mathrm{GSN}_{\text {year }}{ }^{-1}\right)$, and no negative human induced trends were found in the Guizhou Province. This indicates that on-going degradation caused by human activities is mostly pronounced in the Yunnan Province.
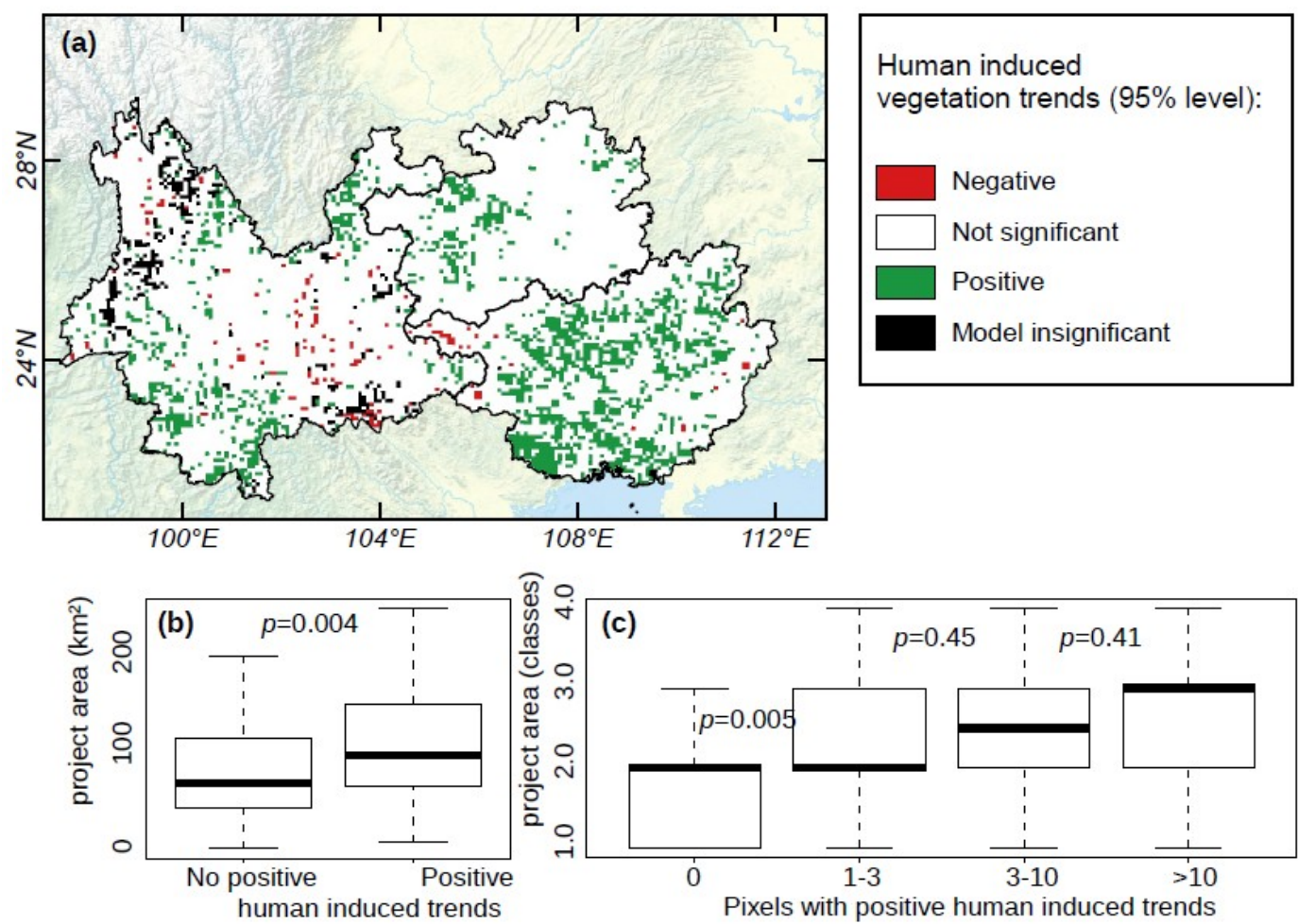

Figure 4 (a) Human induced vegetation trends grouped as significantly positive, negative, and no trend. Pixels without a significant relationship between climate and NDVI are shown in black. (b) The project areas (in $\mathrm{km}^{2}$ ) are compared for counties without and with significant positive human induced trends. (c) The number of pixels with positive human induced trends is compared with the project area (in classes) per county. 
There is a strong significant $(p=0.004)$ relationship between project areas (in $\mathrm{km}^{2}$ ) and positive human induced trends at county scale (Fig. 4b), supporting the methodological assumption of extracting human induced trends. It is clearly shown that positive trends are mostly found in counties with larger project areas and a relation between the number of pixels with positive trends and project area can be observed (Fig. 4c). However, the difference between the groups is not significant and the variation between counties is considerable as larger area does not always imply more positive trends (Fig. 4c). To account for this, we introduce two measures relating the significant ( $95 \%$ level) positive human induced trend with statistical data on conservation projects: (1) the project intensity (a measure of the funding invested per area) and (2) the PEI (a measure of the project effectiveness). At county scale (Fig. 1d), we found 90 counties (out of 291 in total) without any significant increasing human induced trend, indicating no significant project effectiveness. Most of these counties were found in the Yunnan and Guizhou Provinces (Fig. 4a). The shares of pixels with significant increasing human induced trends in other counties were between $0.01(1 \%)$ and $0.86(86 \%)$, with PEI ranging from 0 to 39.

Counties were grouped according to the project effectiveness (high, moderate and low effectiveness) (Fig. 5a-c), comparing the project intensity with the percentage of pixels with a significant positive human induced trend. In total, 55 counties were characterized by a high project effectiveness $(\mathrm{PEI}<1)$ (Fig. 5a) and most of them were concentrated in the Guangxi Province (Fig. 5d). Moderate project effectiveness (PEI between 1 and 10) was found in 115 counties (Fig. 5b). In 31 counties the project effectiveness was low (PEI $>10)$ and these were mainly located in the Yunnan Province (Fig. 5c and Fig. 5d). At county scale, a clear relationship is observed between the invested funding per area (project intensity) and the percentage of positive human induced trends. This relationship is most pronounced in counties with high effectiveness $\left(r^{2}=0.41, p<0.01\right.$, slope $\left.=0.8\right)$, and weakens for the groups with moderate $\left(r^{2}=0.30, p<0.01\right.$, slope $\left.=0.4\right)$ and low effectiveness $\left(r^{2}=0.22\right.$, 306 $p<0.01$, slope $=0.04$ ). 

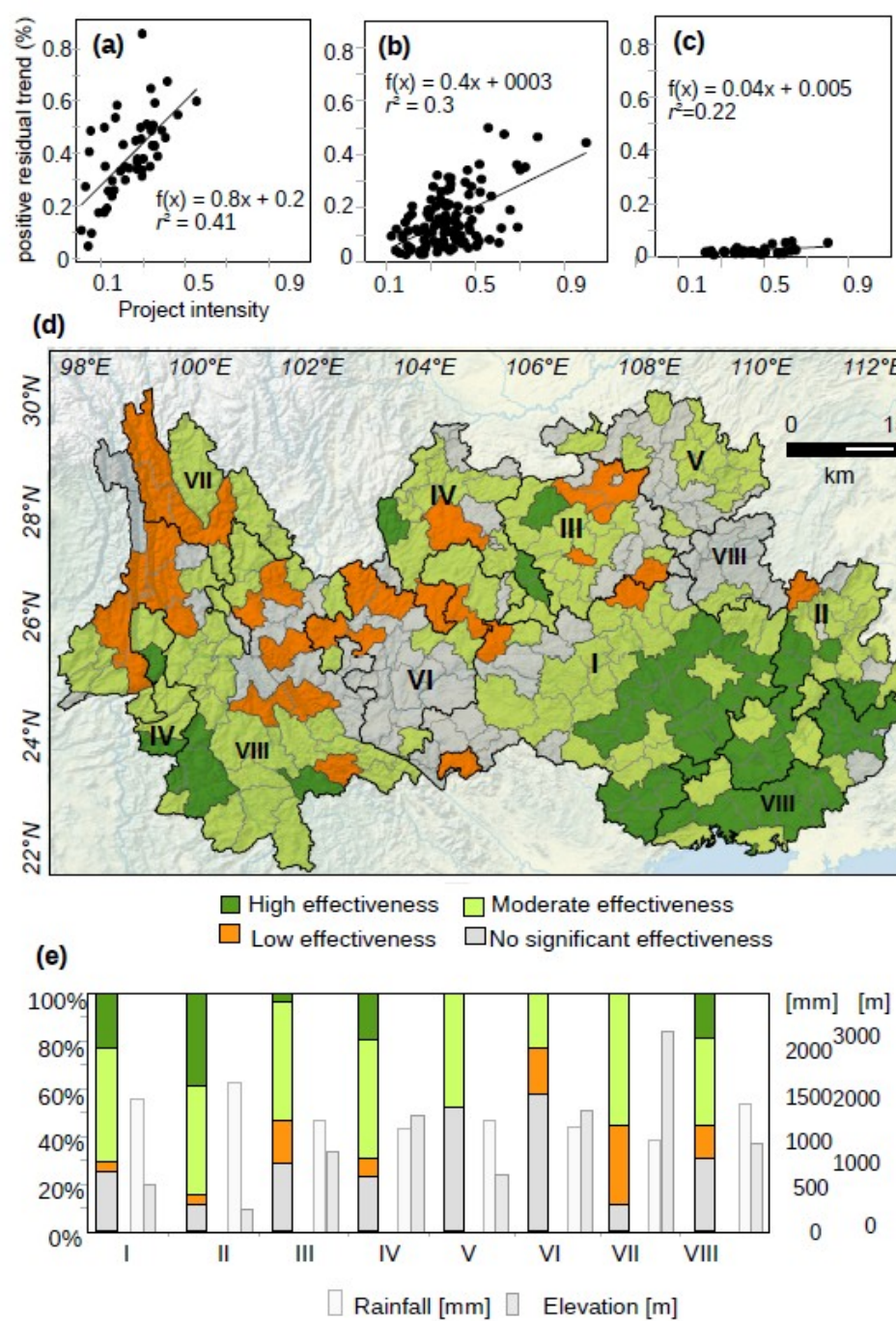

Figure 5 Relationships between the percentage of pixels with significant increasing human induced vegetation trend in a county and the normalized project intensity (funding invested per area). (a) Counties with high project effectiveness; (b) counties with moderate project effectiveness; (c) counties with low project effectiveness. (d) Spatial distribution of the levels of project effectiveness at the county scale and (e) levels of project effectiveness per project region (see Fig. 1c) with associated mean rainfall and elevation.

\section{Spatial differences of vegetation trends under different karst landforms}

Differences in vegetation trends between project regions were analyzed for the entire study period, reference period and conservation period respectively (Fig. 6). The vegetation showed an overall improvement in most of the regions during the entire study period (1982-2011). More specifically, vegetation in the Karst Trough Valley region (V) shows the largest share of increasing vegetation trends (about 83\%), followed by the Karst Peak Forest Plain (II) (78\%) and Karst Plateau (III) (69\%). Vegetation in other regions showed no significant trends, especially in the Middle-high Hill region (VII) (73\%) and Karst Basin region (VI) (64\%). Only a small percentage of the pixels were found to have a decreasing trend. With $2 \%$ in the Karst Basin (VI) and the Karst Gorge region (IV), these are the only regions with a noticeable share of significant decreasing vegetation trends. 
If split into two periods, most pixels during the reference period (1982-2000) showed no significant trends (stable), especially in the Karst Trough Valley (V) (99\%) and Karst Plateau (III) (98\%). The largest share of significant positive trends (increase) was detected in the Peak Forest Plain region (II) (10\%) and the Karst Gorge region (IV) (7\%), respectively.

Regarding human induced vegetation trends during the conservation period (2001-2011), most pixels in each region (76\%) were insignificant, showing no significant impact of human activities, especially in the Karst Trough Valley (V) (95\%) and Karst Basin regions (VI) (94\%). The percentage of pixels with increasing human induced vegetation trends in the Peak Forest Plain (II) and Peak Cluster Depression (I) regions was $23 \%$ and $22 \%$, respectively, which was the largest among all regions. The percentage of pixels with decreasing human induced trends in the Karst Basin region (VI) (3\%) was larger than any other region, being an indication of ongoing human induced degradation.

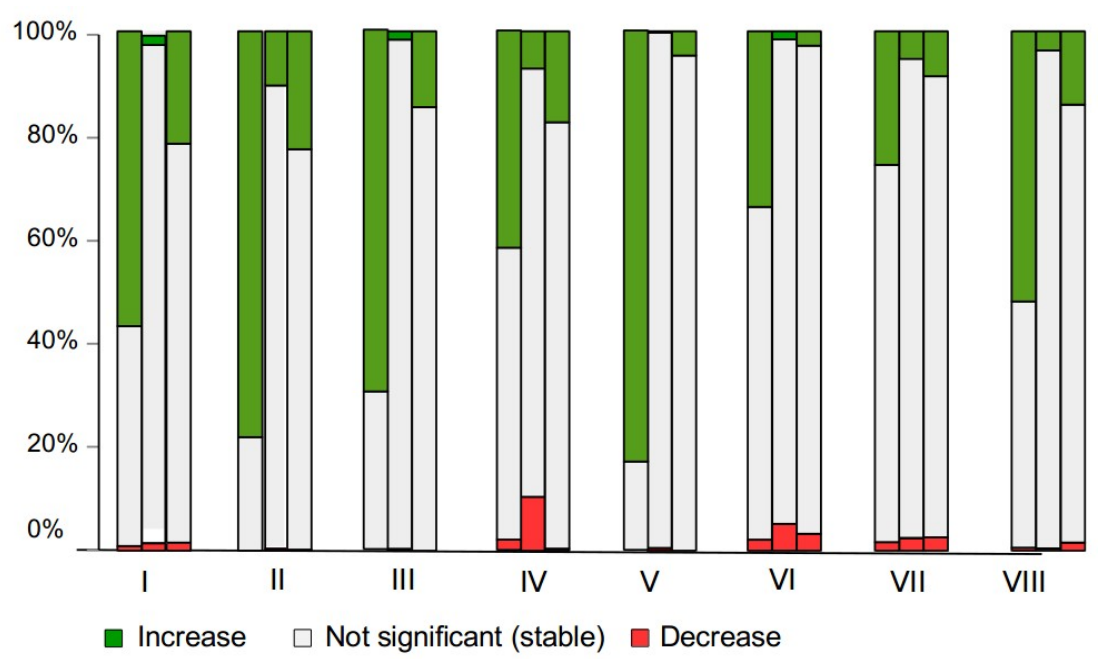

Figure 6 The area ratio (percentage cover) of vegetation trends during different periods (full period:1982-2011 (left bar), reference period:1982-2000 (middle bar) and conservation period: 2001-2011 (right bar)) in different project regions (Fig 1c).

\section{Discussion}

\section{Effectiveness of ERPS variability between different counties}

We identified the effect of invested project funds through the implementation of Ecological Restoration Projects (ERPs) at county scale and found varying results of the Project Effectiveness Index (PEI) indicating different degree or extent of effectiveness of ERPs implementation. Many of the spatial patterns of the PEI can be explained by the interplay between climatic and terrain conditions as well as human management. In the past 30 years, the temperature of Southwest China during the growing season increased significantly $(p<0.01)$, and combined with an insignificant 
( $p>0.01)$ decrease in rainfall (Cai et al., 2014), this has created challenging conditions for newly planted vegetation to survive. Additionally, frequent droughts have become a serious hazard in recent years (Guan et al., 2015; Zhai et al., 2005). For example, the severe drought in 2009 was reported to have adverse impact on the vegetation in the Yunnan, Guizhou and Guangxi Provinces (Barriopedro et al., 2012). Combined with a warm and dry climate, these extreme weather events negatively impact on the survival and growth of planted trees (Wu et al., 2014). High effectiveness of ERPs is mostly found in the Peak Forest Plain (II) and Peak Cluster Depression regions (I) in the Guangxi Province (Fig. 5d). These areas have much more favorable growing conditions $\left(24^{\circ} \mathrm{C}\right.$ and $1662 \mathrm{~mm}$ rainfall) than other regions (Fig. 5e). In contrast, low or no effectiveness was detected in large parts of the Yunnan and Guizhou Provinces and especially the Middle-high Hill (VII) and the Karst Trough Valley (V) regions characterized by unfavorable growing conditions $\left(17^{\circ} \mathrm{C}\right.$ and $1134 \mathrm{~mm}$ rainfall) and rough terrain (high elevation and slope) show low or no effect of ERPs, in spite of high investments.

Apart from climate and terrain, human management plays an important role for the success of ERPs. Proper management includes the selection and planting of species adapted to local climatic conditions, the continuous monitoring of plantations, but also the incorporation and compensation of the local population. The Grain to Green Program aims to transform cropland into ecologic (used for timber production) or economic (orchards or plantations with trees for medical use) forests. The government pays subsidies to the owner of the transformed cropland for 8 year (ecologic forest), 5 years (economic forest) or 2 years (grassland) (Xu et al., 2004). Peasants generally prefer to convert their cropland into forest rather than grassland to receive a higher compensation. However, not all regions are equally well suited for forest growth and in some areas abiotic conditions allow only grass or scrub to grow (Trac et al., 2007). Limited by a low water use efficiency, planted trees grow slowly (or do not grow at all) and the ecological value is thereby questionable (Cao, 2011; Trac et al., 2007; Uchida et al., 2005; Weyerhaeuser et al., 2005). Hence, large investments in tree planting do not necessarily have the expected high effect, if the local conditions are not considered and the selection of inappropriate species resulted in many planting failures (Cao, 2011).

The population of China is growing rapidly leading to an increasing demand for food. The subsidies for conservation received by the peasants do not compensate them adequately, which forces many peasants to return their grass/forest land back into cropland (Trac et al., 2007). Thus, Weyerhaeuser et al. (2005) suggested that the subsidies provided to the peasants should be more attractive and at least compensate for the losses of converting the land for the sustainability of the Grain to Green program. Peasants are willing to participate in initial planting because they are paid for their labor, but they pay less attention to the protection of planted trees/grasses (especially the ecologic forest), since they do not receive any following payment from the government or any economic profit from the ecologic forest. Many areas of implementation are in regions away from urban centers without any project offices and limited access (e.g. northern Yunnan Province), thereby making it difficult for the government to monitor the successfulness of project conservation. This is in 
line with reports of unsuccessful growth of trees/grasses in these regions (Trac et al., 2007).

In contrast to this general pattern, we identified several counties with high effectiveness in spite of unfavorable climatic and terrain conditions. Examples are Shidian in the Yunnan Province and also Qiaojia and Dafang in the Guizhou Province. In depth research at the local scale is needed to identify the reasons and drivers for successful vegetation improvements in these counties. Even though the success is not uniform, we have shown numerous areas with a positive human induced trend, being an indication that projects, if properly implemented, can greatly benefit China in combating desertification (Du, 2001; Xu et al., 2006; Xu and Cao, 2001). However, we also identified areas of low and no effect in spite of high investments, and special attention is needed in these areas to find the reasons for the unsuccessful implementation.

\section{Limitations and uncertainties}

Applying a remote sensing approach in ecological conservation allows for rapid monitoring and mapping of project efforts for large areas over a long time period. There are, however, limitations to the approach as the applied methodology is based on assumptions/choices which may introduce uncertainties. Firstly, there is a trade-off between spatial and temporal resolution. The coarse spatial resolution of the data set used $(8 \mathrm{~km})$ does not allow for the detection of small scale changes, but the GIMMS-3g data used here remains the only available data set for continuous time series analysis dating back to the 1980's with a sufficient quality in regards to the transition between multiple sensors involved (Tian et al., 2015). We thus assume that conservation projects have large scale impact and the footprint of the project efforts is homogeneous and visible within $64 \mathrm{~km}^{2}(8 \mathrm{x} 8 \mathrm{~km})$. This may conceal small scale degradation and especially human activities which are rarely uniform at this scale. Therefore, the results presented primarily give insights at regional (county) scale but less so at the local scale. However, a recent study by Tong et al. (2016) applying MODIS data with a $250 \mathrm{~m}$ resolution (2001 to 2013) showed that for the Guangxi and Guizhou Provinces the overall spatial patterns of vegetation conditions are comparable with the results presented here. Li et al. (2016) also applied the RESTREND method using MODIS data for the Bejing-Tianjin Sand Source region in China thereby providing results with more spatial details than the current study. However, since MODIS is only available since 2000, Li et al. (2016) were not able to develop the NDVI-climate model for a period without project influences, which lowers the reliability of the assessment of the specific impact from ERPs. Secondly, this study uses a vegetation index (NDVI) as proxy for ecosystem health. NDVI has shown to be a function of herbaceous and woody cover and density, soil and vegetation color and soil moisture, and is widely used to measure the chlorophyll abundance in vegetation. However, NDVI does not provide information on the vegetation and species composition. Moreover, the average NDVI over the growing season months serves as a robust proxy for the net primary production of this period, but does not take into account spatial and inter-annual 
dynamics/changes in plant phenology, land cover and climate.

\section{Conclusions}

Climate changes and human activities drive vegetation trends in Southwest China. This study evaluated the effectiveness of Ecological Restoration Projects (ERPs), more specifically the Grain to Green Program, by developing a NDVI-climate model for a reference period (1982-2000), and predicting the annual growing season NDVI (GSN) for the period 2001 to 2011 to quantify the effects of project activities on vegetation trends. These human induced trends were found to be related to conservation projects and the following conclusions can be drawn:

(1) After a period of an overall decrease (1982-2000), vegetation increased in most areas between 2001 and 2011. The largest rate of increase was found in the Guangxi Province.

(2) Vegetation improvement caused by ERPs accounted for 15\%, whereas vegetation degradation induced by human activities covered $1 \%$. Human activities showed no significant impact on vegetation dynamics in other regions (84\%). The ERPs implemented in the Guangxi Province had a larger positive effect on vegetation dynamics than in other provinces. Human activities in the Yunnan Province had a larger negative effect on vegetation than in the Guangxi Province.

(3) Vegetation improved more in the Peak Forest Plain and the Peak cluster Depression than in other regions during 2001-2011, whereas vegetation degradation caused by human activities was mostly pronounced in Karst Basin regions.

(4) There was a significant relationship between positive human induced trends and project intensity (funding invested per area). In total, 55 counties showed high project effectiveness as measured by the Project Effectiveness Index (PEI), 115 counties were characterized by moderate project effectiveness and 31 counties had low project effectiveness. No significant effects of project implementation were detected in the remaining 90 counties.

(5) Even though areas characterized by high project effectiveness were found, this does not apply to the entire study area, and especially areas with an unfavorable climate, rough terrain conditions and poor management practices (unsuitable species selection, low compensation rate for farmers) show limited or no effect of project implementation.

(6) Remote sensing has shown to be a valuable tool for monitoring the effectiveness of conservation project. However, the coarse spatial resolution of the data set used leaves uncertainties which can only be overcome by field studies combined with temporal snap-shots of higher resolution imagery.

\section{Acknowledgments:}

This work was supported by the Science and Technology Service Network Initiative (No. KFJEW-STS-092), Chinese Academy of Sciences "Light of West China" Program, National Natural Science Foundation of China (Grant No. 41471445, 41371418), and European Union's Horizon 2020 
research and innovation program under the Marie Sklodowska-Curie (Grant No. 656564). We thank GIMMS NDVI Group for producing and sharing the NDVI dataset. China Meteorological Administration and the National Meteorological Information Center is thanked for sharing the climatic data. We also thank the Forestry Bureau of the Yunnan, Guizhou and Guangxi Provinces for providing the statistical data. The authors want to thank Bo Hong for helping with data processing.

\section{References:}

Archer, E.R.M., 2004. Beyond the "climate versus grazing" impasse: using remote sensing to investigate the effects of grazing system choice on vegetation cover in the eastern Karoo. J. Arid Environ. 57, 381-408.

Barriopedro, D., Gouveia, C.M., Trigo, R.M., Wang, L., 2012. The 2009/10 Drought in China: Possible Causes and Impacts on Vegetation. J. Hydrometeorol. 13, 1251-1267.

Cai, H., Yang, X., Wang, K., Xiao, L., 2014. Is Forest Restoration in the Southwest China Karst Promoted Mainly by Climate Change or Human-Induced Factors? Remote Sens. 6, 98959910.

Cao, S., 2011. Impact of China's Large-Scale Ecological Restoration Program on the Environment in and Society in Arid and Semiarid Areas of China: Achievements, Problems, Synthesis, and Applications. Crit. Rev. Environ. Sci. Technol. 41, 317-335.

Cao, S., L.C., 2011. Excessive reliance on afforestation in China's arid and semi-arid regions: Lessons in ecological restoration. Earth-Sci. Rev. - EARTH-SCI REV 104, 240-245.

Cao, X., Gu, Z., Chen, J., Liu, J., Shi, P., 2006. Analysis of human-induced steppe degradation based on remote sensing in Xinlin Gole, Inner Mongolia, China. Journal of Plant Ecology 30 (2), 268-277. (In Chinese)

Chatterjee, S., Bisai, D., Khan, A., 2014. Detection of Approximate Potential Trend Turning Points in Temperature Time Series (1941-2010) for Asansol Weather Observation Station, West Bengal, India. Atmospheric Clim. Sci. 4, 64-69.

Choi, Y.D., 2004. Theories for ecological restoration in changing environment: Toward "futuristic" restoration. Ecol. Res. 19, 75-81.

Du, S.F., 2001. Environmental Economics; Encyclopedia Press: Beijing, China.

Evans, J., Geerken, R., 2004. Discrimination between climate and human-induced dryland degradation. J. Arid Environ. 57, 535-554.

Fensholt, R., Proud, S.R., 2012. Evaluation of Earth Observation based global long term vegetation trends - Comparing GIMMS and MODIS global NDVI time series. Remote Sens. Environ. $119,131-147$.

Guan, Y., Zheng, F., Zhang, P., Qin, C., 2015. Spatial and temporal changes of meteorological disasters in China during 1950-2013. Nat. Hazards 75, 2607-2623.

He, C., Tian, J., Gao, B., Zhao, Y., 2015. Differentiating climate- and human-induced drivers of grassland degradation in the Liao River Basin, China. Environ. Monit. Assess. 187.

Herrmann, S.M., Anyamba, A., Tucker, C.J., 2005. Recent trends in vegetation dynamics in the African Sahel and their relationship to climate. Glob. Environ. Change 15, 394-404.

Horion, S., Prishchepov, A.V., Verbesselt, J., de Beurs, K., Tagesson, T., Fensholt, R., 2016. Revealing turning points in ecosystem functioning over the Northern Eurasian agricultural frontier. Glob. Change Biol. 22, 2801-2817.

Huang, L., Xiao, T., Zhao, Z., Sun, C., Liu, J., Shao, Q., Fan, J., Wang, J., 2013. Effects of grassland restoration programs on ecosystems in arid and semiarid China. J. Environ. Manage. 117, 268-275.

Huber, S., Fensholt, R., Rasmussen, K., 2011. Water availability as the driver of vegetation dynamics in the African Sahel from 1982 to 2007. Glob. Planet. Change 76, 186-195.

Huete, A., Didan, K., Miura, T., Rodriguez, E.P., Gao, X., Ferreira, L.G., 2002. Overview of the radiometric and biophysical performance of the MODIS vegetation indices. Remote Sens. Environ., The Moderate Resolution Imaging Spectroradiometer (MODIS): a new generation of Land Surface Monitoring 83, 195-213. 
Jia, X., Fu, B., Feng, X., Hou, G., Liu, Y., Wang, X., 2014. The tradeoff and synergy between ecosystem services in the Grain-for-Green areas in Northern Shaanxi, China. Ecol. Indic. 43, $103-113$.

Jiang, Z., Lian, Y., Qin, X., 2014. Rocky desertification in Southwest China: Impacts, causes, and restoration. Earth-Sci. Rev. 132, 1-12.

Li, A., Wu, J., Huang, J., 2012. Distinguishing between human-induced and climate-driven vegetation changes: a critical application of RESTREND in inner Mongolia. Landsc. Ecol. 27, 969-982.

Li, H., Cai, Y., Chen, R., Chen, Q.,Yang, X., 2011. Effect assessment of the project of grain for green in the karst region in Southwestern China: a case study of Bijie Prefecture. Acta Ecologica Sinica. 31(12), 3255-3264. (In Chinese)

Li, X., Wang, H., Zhou, S., Sun, B., Gao, Z., 2016. Did ecological engineering projects have a significant effect on large-scale vegetation restoration in Beijing-Tianjin Sand Source Region, China? A remote sensing approach. Chin. Geogr. Sci. 26, 216-228.

Li, X.R., Jia, X.H., Dong, G.R., 2006. Influence of desertification on vegetation pattern variations in the cold semi-arid grasslands of Qinghai-Tibet Plateau, North-west China. J. Arid Environ. 64, 505-522.

Liu, D., Chen, Y., Cai, W., Dong, W., Xiao, J., Chen, J., Zhang, H., Xia, J., Yuan, W., 2014. The contribution of China's Grain to Green Program to carbon sequestration. Landsc. Ecol. 29, $1675-1688$.

Liu, Y., Wang, J., Deng, X., 2008. Rocky land desertification and its driving forces in the karst areas of rural Guangxi, Southwest China. J. Mt. Sci. 5, 350-357.

Mbow, C., Fensholt, R., Rasmussen, K., Diop, D., 2013. Can vegetation productivity be derived from greenness in a semi-arid environment? Evidence from ground-based measurements. J. Arid Environ. 97, 56-65.

Mohsin, T., Gough, W.A., 2009. Trend analysis of long-term temperature time series in the Greater Toronto Area (GTA). Theor. Appl. Climatol. 101, 311-327.

Nemani, R.R., Keeling, C.D., Hashimoto, H., Jolly, W.M., Piper, S.C., Tucker, C.J., Myneni, R.B., Running, S.W., 2003. Climate-Driven Increases in Global Terrestrial Net Primary Production from 1982 to 1999 . Science $300,1560-1563$.

Pettorelli, N., Vik, J.O., Mysterud, A., Gaillard, J.-M., Tucker, C.J., Stenseth, N.C., 2005. Using the satellite-derived NDVI to assess ecological responses to environmental change. Trends Ecol. Evol. 20, 503-510.

Pinzon, J.E., Tucker, C.J., 2014. A Non-Stationary 1981-2012 AVHRR NDVI3g Time Series. Remote Sens. 6, 6929-6960.

Running, S.W., Nemani, R.R., 1988. Relating seasonal patterns of the AVHRR vegetation index to simulated photosynthesis and transpiration of forests in different climates. Remote Sens. Environ. 24, 347-367.

Seabrook, L., Mcalpine, C.A., Bowen, M.E., 2011. Restore, repair or reinvent: Options for sustainable landscapes in a changing climate. Landsc. Urban Plan., Landscape and Urban Planning at 100 100, 407-410.

State Forestry Administration Bureau (SFAB), 2000. Guojia jiwei he linyeju di 111 hao wenjian-

Guanyu jinyibu zuohao tuigeng huanlin huancao shidian gongzuo de jianyi (The 111th document issued Department of Planning, Forestry Administration Bureau: Appendix: Implementation Proposals for Grain-for-Green policy in the Upper Reaches of the Yangtze River and the Upper and Middle Reaches of the Yellow River). 26.

Tian, F., Fensholt, R., Verbesselt, J., Grogan, K., Horion, S., Wang, Y., 2015. Evaluating temporal consistency of long-term global NDVI datasets for trend analysis. Remote Sens. Environ. 163, 326-340. doi:10.1016/j.rse.2015.03.031

Tong, L., Liu, C., Nie, H., 2009. Remote Sensing Investigation and Study on the Evolution of China South Karst Rocky Desertification Areas; Science Press: Beijing, China,

Tong, X., Wang, K., Brandt, M., Yue, Y., Liao, C., Fensholt, R., 2016. Assessing Future Vegetation Trends and Restoration Prospects in the Karst Regions of Southwest China. Remote Sens. 8, 357.

Tong, X., Wang, K., Yue, Y., Liao, C., Xu, Y., Zhu, H., 2014.Trends in vegetation and their responses to climate and topography in northwest Guangxi. Acta Ecol. Sin. 34, 1-10. (In Chinese)

Trac, C.J., Harrell, S., Hinckley, T.M., Henck, A.C., 2007. Reforestation programs in Southwest China: Reported success, observed failure, and the reasons why. J. Mt. Sci. 4, $275-292$. 
Tucker, C.J., Slayback, D.A., Pinzon, J.E., Los, S.O., Myneni, R.B., Taylor, M.G., 2001. Higher northern latitude normalized difference vegetation index and growing season trends from 1982 to 1999. Int. J. Biometeorol. 45, 184-190.

Uchida, E., Xu, J., Rozelle, S., 2005. Grain for Green: Cost-Effectiveness and Sustainability of China's Conservation Set-Aside Program. Land Econ. 81, 247-264.

Wang, J., Guo, N., Cai, D., Deng, Z., 2009.The effect evaluation of the program of restoring grazing to grasslands in Maqu County. Acta Ecol. ica Sinica 29 (3), 1276-1284. (In Chinese)

Wang, J., Meng, J.J., Cai, Y.L., 2007. Assessing vegetation dynamics impacted by climate change in the southwestern karst region of China with AVHRR NDVI and AVHRR NPP time-series. Environ. Geol. 54, 1185-1195.

Wang, S.J., Liu, Q.-M., Zhang, D.-F., 2004. Karst rocky desertification in southwestern China: geomorphology, landuse, impact and rehabilitation. Land Degrad. Dev. 15, 115-121.

Wessels, K.J., Prince, S.D., Malherbe, J., Small, J., Frost, P.E., VanZyl, D., 2007. Can human-induced land degradation be distinguished from the effects of rainfall variability? A case study in South Africa. J. Arid Environ. 68, 271-297.

Weyerhaeuser, H., Wilkes, A., Kahrl, F., 2005. Local impacts and responses to regional forest conservation and rehabilitation programs in China's northwest Yunnan province. Agric. Syst., Local Land Use Strategies in a Globalizing World: Subsistence Farming, Cash Crops and Income Diversification 85, 234-253.

Wu, Z., Wu, J., He, B., Liu, J., Wang, Q., Zhang, H., Liu, Y., 2014. Drought Offset Ecological Restoration Program-Induced Increase in Vegetation Activity in the Beijing-Tianjin Sand Source Region, China. Environ. Sci. Technol. 48, 12108-12117.

Wu, Z., Wu, J., Liu, J., He, B., Lei, T., Wang, Q., 2013. Increasing terrestrial vegetation activity of ecological restoration program in the Beijing-Tianjin Sand Source Region of China. Ecol. Eng. 52, 37-50.

Xiao, X., Wang, Y., Jiang, S., Ojima, D.S., Bonham, C.D., 1995. Interannual variation in the climate and above-ground biomass of Leymus chinense steppe and Stipa grandis steppe in the Xilin river basin, Inner Mongolia, China. J. Arid Environ. 31, 283-299.

$\mathrm{Xu}$, E.Q., Zhang, H.Q., 2014. Characterization and interaction of driving factors in karst rocky desertification: a case study from Changshun, China. Solid Earth 5, 1329-1340.

Xu, J., Yin, R., Li, Z., Liu, C., 2006. China's ecological rehabilitation: Unprecedented efforts, dramatic impacts, and requisite policies. Ecol. Econ. 57, 595-607.

Xu, J.T., Cao, Y.Y., 2001. Converting steep cropland to forest and grassland: efficiency and prospect of sustainability. International Economic Review. 2, 56-60. (In Chinese)

Xu, Z., Bennett, M.T., Tao, R., Xu, J., 2004. China's Sloping Land Conversion Program Four Years on: Current Situation and Pending Issues. Int. For. Rev. 6, 317-326.

Yuan, D., 1997. Rock desertification in the subtropical karst of south China; Gebrüder Bornträger: Stuttgart, Germany.

Yuan, D., 2014. The Research and Countermeasures of Major Environmental Geological Problems in Karst Areas of Southwest China; Science Press: Beijing, China.

Yue, Y., Zhang, B., Wang, K., Liu, B., Li, R., Jiao, Q., Yang, Q., Zhang, M., 2010. Spectral indices for estimating ecological indicators of karst rocky desertification. Int. J. Remote Sens. 31, $2115-2122$.

Zhai, P., Zhang, X., Wan, H., Pan, X., 2005. Trends in Total Precipitation and Frequency of Daily Precipitation Extremes over China. J. Clim. 18, 1096-1108.

Zhang, G., Dong, J., Xiao, X., Hu, Z., Sheldon, S., 2012. Effectiveness of ecological restoration projects in Horqin Sandy Land, China based on SPOT-VGT NDVI data. Ecol. Eng. 38, 20 29.

Zhang, Y., Peng, C., Li, W., Tian, L., Zhu, Q., Chen, H., Fang, X., Zhang, G., Liu, G., Mu, X., Li, Z., Li, S., Yang, Y., Wang, J., Xiao, X., 2016. Multiple afforestation programs accelerate the greenness in the "Three North" region of China from 1982 to 2013. Ecol. Indic. 61, Part 2, 404-412. 